DOI:10.5392/I.JoC.2010.6.3.038

\title{
A Study on the Research of Big Five Personality Factors Affecting Creativity - The Case of K Institute -
}

\author{
Kil-Whoan Lee, Ha-Sik Song \\ Dept. of Business Administration \\ Chungbuk University, Cheong Ju City, Korea \\ Jin-Hee Park \\ Dept. of Technology Administration \\ University of Technology and Education, Cheon An City, Korea
}

\begin{abstract}
In this study, five personality types of employees have any impact on their creativity, a systematic and comprehensive study of literary research and demonstration studies were parallel. Results of the research employee of the extroversion, agreeableness of their creativity (+) showed the impact. In addition, sincerity, openness to experience, personality and creativity of employee creativity (+) for influencing said. Neuroticism to creativity, but nature does not affect any found. This study, five personality types that affect employee creativity of individuals by examining the relationship between personality type and creativity by presenting a model for the study, employees' personality types can have on creativity and offers a realistic alternative to the theory presented you can find the meaning in that. These theoretical and empirical validation of the results of employee productivity oriented organizations, including human resource management in a systematic and reasonable for the type of personality tests are being conducted on the administrative feasibility is expected to be able to provide. Finally, based on the results of these studies, management and administrative implications and future research directions presented.
\end{abstract}

Key words: personality, big five personality factor, creativity

\section{INTRODUCTION}

Under the current uncertain environment, the existing way of thinking in the organization technical innovation and service innovation, and innovation needs of customers, and to this organization to build a more efficient process than the creative process and to build more time is needed. Depending on the request today, this contemporary creativity of individuals, organizations and countries is essential to the survival strategy is considered as one. The recent rapid environmental changes are happening in the globalization phenomenon and as individuals and their organizations solve the existing problems in new ways to troubleshoot a different approach is required. As a result, many individuals and organizations increasingly recognize the need to be creative to change this perception was being spread across the social hierarchy. Therefore, the most creative social scientists' research has been the subject of interest (Bak, 2001).

\footnotetext{
*Corresponding author.E-mail :khyibsh@nate.com Manuscript received May. 03, 2010 ; accepted Aug. 18, 2010
}

Amabile(1998) "The creativity is still the fundamental changes taking place in the world organization is a key element for success," he was referring to its importance. Kanter (1983), scientists and other members of the organization when the creative work of these organizations to develop new and useful products, ideas, procedures, and can offer members of the creative achievements of these organizations to respond effectively to their changing environment can be claims were. The spirit of creativity of members of the organization is the most important factor in the growth and development (Kim, 1997). Suvagondh (2003) is members of organizations to promote creativity and culture to create an organization must identify each claim was the difference. The high level of effectiveness, efficiency, and productivity in order to seek ways to accommodate individual differences in their claims were to consider.

Members of the organization, individual characteristics such creativity and creative processes that lead to leadership, organizational support for the creative process, and the interaction between members and many other factor that influence, but in this study, the specific nature of individual creative action of the type of research is to study about the 
impact.

Recently, member of the organization of organizational performance and personality characteristics related to increasing interest is the trend. System theory in organizational behavior research conditions relative to the development of the theory were not getting the attention of the variable nature of human relationships and organizational performance to new issues incidence has emerged as an important research topic.

Indeed, members of the organization of the creative act in an uncertain organizational environment that contributes to the survival of an organization called the most important factor in view, this creative action affects the personal nature of the elephant research chapter will provide an interesting study.

So far, many types of personality psychologists have uncovered, but they also obscure the many differences between the concepts, the concept of the zone is too narrow does not mean the type they were very practical. However, recent organizational scholars and practitioners among the big five theory of personality organization, management and relevant about the fact that consensus has been (Baek, 2002). Usually defined as a comprehensive nature and represent an individual's personality, relative to a fixed structure is used to describe the big five model. This model describes the individual or individuals to classify many of the characteristics, including 5 types were used. The organization represented in the study of nature has been used as a representative. Big five model of Norman (1963) formally proposed in the academic attention has been steady since. Since the big five model, support for the proposed study has been made continuously, until recently, many studies have demonstrated the feasibility of this model.

These scholars based their research in this study, the relationship between big five personality type and creativity were validates want.

\section{LITERATURE REVIEW}

\subsection{Big Five personality model on survey}

Norman(1963) for the five factor model proposed by academics aggressive five factors model has begun to receive attention. The five factors' extroversion', 'agreeableness', 'neuroticism', 'conscientiousness', 'openness to the experience' was dubbed. 5-factor model, this instrument continues to support research led, in many recent studies have demonstrated the validity of the model has five factors.

5 factors in the model to study three kinds of approaches have been used. The second approach is based on several different personality theory personality tests to analyze the nature of the factors that many researchers find check the dimensions of the existing nature of the relationship between the five factors, five factors are fit through the analysis said. Final approach to analyze the silence from multiple sources to find out the dimensions of personality calm self or others, even from five factors typically it come properly revealed. Name the five kinds of factors for each scholar, but a fundamental difference between some of the content is the same.

The first factor 'extrovert (extroversion)' as the others want to interact with others of interest indicates the degree. Attribute export-oriented factors are associated with aggressiveness, sociability, self-day wall, wild, scrupulosity and is bidirectional.

The second factor 'propensity neurosis (Neuroticism)', as many worried, tense and anxious and depressed and capricious severe, depressed and moody, fretful and will indicate the amount. The other attributes in the dimension of neurosis, emotionally stable, and how well they can control how the world is threatening the world indicates the extent not think. Norman the emotional stability of the factors (emotional stability) was called.

The third factor affinity (agreeableness) as a harmonious relationship with others and to maintain a comfortable enough to represent. The highest score factors seem friendly people who are respectful, collaborative, generous, and compromise, and patience, and giving attention to detail, has a soft heart, altruistic have been characterized. Low scores on the other hand, people seem hostile, indifferent for others and selfcentered, jealous, shows many characteristics. This factor Guilford \& Zimmerman(1949) that 'friendliness' he was called, Fiske(1949) that 'social sympathy (social conformity)' he was named.

The fourth factor is 'conscientiousness' social rules, norms, principles, willing to protect them shows the degree. Conscientiousness high score on factor that people seem to work, carefully and thoroughly, and a strong sense of responsibility, planning, giving credibility to represent the attribute. Tupes \& Christal(1961) that the factors 'reliability(dependability)' is grown to, Fiske(1949) that 'achievement will (will to achieve)' was named.

The fifth factor, openness to experience as the intellectual stimulation, change, diversity, represents the desired level. Factors seem to score high on openness they have imagination and creative, challenging and rich in culture and curiosity, many new things and open, and pointed to the sensitive nature. These attributes have a genetic rather than a home environment, education, cultural background and is known to appear as a result. Among these five factors, constructs about the nature of consent when considering the export-oriented psychologists, neurosis, friendliness factor sincerity, openness to experience factor has been more than the conscientiousness (Kim \& Yu, 1997).

Table 1. Big Five Personality Type

\begin{tabular}{|c|c|}
\hline Personality Type & Personality Character \\
\hline Agreeableness & $\begin{array}{l}\text { graciousness, elegant, plenty of compassion, } \\
\text { good care }\end{array}$ \\
\hline Conscientiousness & constraint, reliable, strong self-abstinence \\
\hline Neuroticism & $\begin{array}{l}\text { plenty of worry, anxiety, freak, depress, } \\
\text { particularity, anger imitable }\end{array}$ \\
\hline Extroversion & activity, likes to say, eligibility, confident \\
\hline Openness to Experience & $\begin{array}{l}\text { sensitive, flexibility, creativity, plenty of } \\
\text { curiosity }\end{array}$ \\
\hline
\end{tabular}


Source: Baekgibok(2002), "Organizational Behavior Research", Changminsa, pp.51-53.

\subsection{Individual-level theories about creativity survey}

Personal level of creativity in the field of psychological research has been primarily of interest for the main prerequisite, personality, cognitive abilities, inner motivation, and knowledge is (Choe, 1995).

Creativity at the individual level, the study identifies personality factors, cognitive factors, internal motivation, and knowledge can be distinguished. The study of individual factors and personality a study to identify the relationship between creativity is limited only by individual factors personality theoretical studies were in progress.

In Korea, leading the researchers to scientific research and creative behavior and personality characteristics of people asking whether the results (Choe, 1998), they also unusual adjectives has been described as. According to the Gallup poll of industry knowledge and leading-edge American people about the creative people who have absorbed the stereotype that his stay at the work of others, social responsibility and showed indifference (Choe, 1998).

Gardner(1993) that Freud, Gandhi, Einstein, Stravinsky and superior creative talent are ranked in order claims to have had a different side of life, Campbell is synchronized with the pressure to bear on ethical and moral boundaries of the claim Pass were (Choe, 1998). Creative people, but about the physical characteristics of the empirical studies conclude that aggregates look down as much as they fulfill their creative nature of the window, doing wonderfully diverse short summary of their characteristics is a kind of tenuous factual basis 'myth' to say can be.

Lately, Sternberg (1999), this extensive list of personality characteristics in common with the five attributes always has said appearance. He said creative attributes as ambiguous for the patient, patience, openness to new experiences, willing to risk the spirit, and was confident about them.

Csikszentmihalyi(1996) and creative figures, including Nobel Prize winners by interviewing 100 people, research and study attributes a significant portion quoted above, as well as match these characteristics, as well as those being implemented in more depth about the context information is available. To fulfill their creative attributes and values that help most of the things listed in the order mentioned the relationship, family, and intrinsic motivation, social interest, independence, education, excellence, balance, responsibility, curiosity, a thorough knowledge of the prepare a variety of interests, openness, courage, and time alone, and had integrity.

Existing research on the characteristics of creative people, if it was listed, a new view of personality research is looking at properties. In order to accomplish that creative combination of personality characteristics confronting research that is needed. Personality characteristics of creative people for a variety of one, it can be divided into 10 large dimensions, each of these dimensions was divided into opposing the anode (eg: introvert vs extrovert) looks. The remarkable thing about this study, creative people are with them all the features of both extremes, depending on the situation will look different look. Say, is sometimes quite improvised, and sometimes very well-planned will also (Choe, 1998).

Research related to the nature of creativity, researchers differ, but appear relatively consistent characteristics sum it up, in terms of experience, highly valued for aesthetic characteristics, broad interests, attraction to complexity, high energy, independent judgment, autonomy, intuition, confidence, selfcontradictory about the concept of conflict resolution skills and the ability to accept the situation, strong self-concept include(Barron \& Harrington, 1981).

Recently, researchers generally related to the creativity of nature, but lacks the creative nature of screening is generally agreed (Lee, 2003). However, the personal nature of this research directly related to creativity, even if this does not contribute to the creative process and creative work environment by affecting the interaction of creativity under the research program was assumed.

\subsection{Research related to personality type and job performance}

Recently the organization adopted team grows individual team members as well as cognitive ability or job knowledge to maintain harmonious relationship between interpersonal skills and personality is highlighted. In most of the job analysis study performed the tasks of the job that was his job to be officially recognized, the organization's core functions (technical core) that runs directly into the technical part of the process, or core functions by providing the necessary goods indirectly contributes to organizational effectiveness activities are focused. However, only perform this task is not just an organization's effectiveness and related activities. Borman \& Motowidlo(1993) to perform the duties in addition to performing the tasks performed by including the context of performance that gave the area proposed to extend. The context of performing a specific task, but not always necessary to achieve the smooth functioning of teams and organizations as necessary for action, task, activities and business processes (process) as a lubricant organizational, social and psychological environment(context) and organizational form effectiveness of actions refers to contribute. Perform context of helping a colleague, will support the organization's goals, additional work or responsibilities to perform voluntary actions are included. In particular, Borman \&Motowidlo(1993) that (1)successfully completed their task activities necessary for the additional continued passion and commitment, (2)is not an official part of the job, but the task of voluntary activities performed, (3)cooperation with others, helping others, (4)personally uncomfortable whenever the organization that follows the rules and procedures, (5)organizational goals backs, followed, five kinds of support, such as a proposed classification system was.

\section{METHODOLOGY}

\subsection{Definition and Construct Measurement}

\subsubsection{Definition of Construct}


1) Big-five personality types

(1) Extroversion

Extroversion is a gregarious extrovert, like meetings, external stimuli like the excitement and the enthusiastic and cheerful, active and strong opinions about the means of social, stimulus seeking, and perky inclination says.

(2) Agreeableness

Agreeableness that help explain sex dimensional people like to express affection and trust and compliance easier and to help others, and others with care and compassion favor degree means compassionate, honesty, altruism, compliant castles means the degree.

(3) Conscientiousness

Others do not do anything good faith castle itself well, for very thoughtful, planned and organized this, and follow certain rules, it means much, order, watchfulness, the degree of synchronization means a lot of.

(4) Neuroticism

Adapted from the everyday nature about neurosis and anxiety, fear, depression, and implies guilt.

(5) Openness to experience

Openness to experience, imaginative and absorbing, rich in emotional and psychological sensitivity, the sensitivity of inner feelings, preference changes trends, intellectual curiosity, or refers to voluntary confused about falling, imaginative, emotional, intellectual curiosity about the many means.

2) Creativity

Personal creativity as an inherent motivated individuals based on their expertise with a flexible cognitive navigation.

\subsubsection{Construction Measurement}

All construct measurements in this study are as follows (Table 2)

Table 2. Construct Measurement

\begin{tabular}{|c|c|c|c|}
\hline \multicolumn{2}{|c|}{ construct } & $\begin{array}{l}\text { measurement } \\
\text { item }\end{array}$ & $\begin{array}{l}\text { Supporting } \\
\text { Literature }\end{array}$ \\
\hline \multirow{5}{*}{$\begin{array}{l}\text { big five } \\
\text { personality } \\
\text { type }\end{array}$} & extroversion & $\begin{array}{c}\text { I. number } \\
1-5\end{array}$ & \multirow{5}{*}{$\begin{array}{c}\text { Costa \& } \\
\text { McGrae(1992) } \\
\text { Anchanggyu, } \\
\text { Yigyeongim } \\
\text { (1996) }\end{array}$} \\
\hline & agreeableness & $\begin{array}{c}\text { I. number } \\
6-10\end{array}$ & \\
\hline & conscientiousness & $\begin{array}{c}\text { I. number } \\
11-15\end{array}$ & \\
\hline & neuroticism & $\begin{array}{l}\text { I. number } \\
16-20\end{array}$ & \\
\hline & $\begin{array}{l}\text { openness to } \\
\text { experience }\end{array}$ & $\begin{array}{l}\text { I. number } \\
21-25\end{array}$ & \\
\hline \multicolumn{2}{|c|}{ creativity } & $\begin{array}{c}\text { II. number } \\
1-9\end{array}$ & $\begin{array}{c}\text { Kirton \& Ettlie \& } \\
\text { O'keefe (1988) } \\
\text { Choejongin } \\
(1995)\end{array}$ \\
\hline \multicolumn{2}{|c|}{$\begin{array}{l}\text { demographic } \\
\text { variable }\end{array}$} & \multicolumn{2}{|c|}{ III. number 1-8 } \\
\hline
\end{tabular}

\subsection{Research Model and Hypothesis}

On the basis of literature review, we could found each variables (employee big five personality factor, creativity) relationship, so we found this research model and hypothesis.

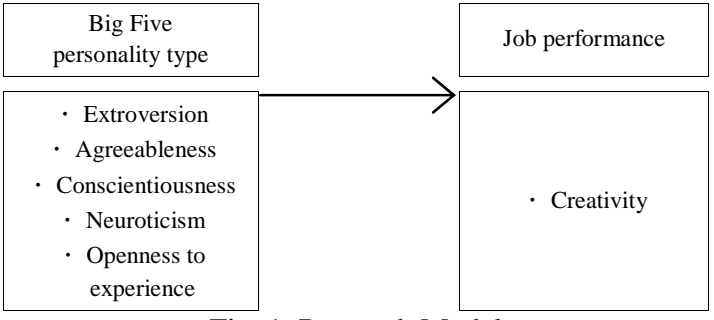

Fig. 1. Research Model

Extroversion who love to socialize and meetings, active and claim he's good. I like the stimulation and excitement, is enthusiastic and optimistic, enterprising, adventurous job in a rich and interesting feel. Kim \& Yu(1997), the outgoing acting organization, and dedication to duty, others for help with behavior, mood inspires action, share information and suggestions for action claims were significantly affected. In addition, Lee (2004) and other research organizations immersed in sex and outgoing communication in the organization showed no significant impact. This leading research based on the following hypothesis was set up.

\section{H. I : Extraversion employee more closely and will have a positive impact on creativity.}

Agreeableness is courteous in personal relationship, but relatively demanding sweet, a tendency to be nice to other means. Others who rely on highly-friendly and has the interest to others, inclined to be frank and social participation compliance, customer behavior, and organizational norms for submitted to comply with the act and are closely associated. Lee(2004) and other research organizations immersed in sex and issue-friendly communication impact on the presentation said. However, Kim \& Yu(2002) study of sex-friendly organizations in the formulation of organizational behavior and compliance, and strong correlation with the centralization. The personal nature of the agreeableness attitude and a cooperative attitude encourage a positive impact, but a challenge to a new area and negatively affect the attitudes inquisitive say can be seen. Based on these findings the following hypotheses were set up.

\section{H. II : Agreeableness employee more closely in a positive impact on creativity and at the same time will have a negative impact.}

Some people have sex as sincere in what and how enthusiastic job with patience and try to handle efficiently and completely is a tendency. Integrity within the organization what are given a highly committed and accurate processing business and pursue new challenges, and personal days do not waste your time. Kim \& $Y u(2002)$ study of sex in the good faith commitment to the organization and job actions, help others, behavior, mood inspires action, information sharing and suggest actions to show the strongest correlation is represented. The seats and Song \& Kim(2002), the integrity of the research organization for sex reflect the ownership loyalty behavior, 
information sharing and encourage behavior that represents the proposed action, and work colleagues about the responsibility and cooperative representing the community to participate in a functional manner the claim was shown a strong correlation. Based on these studies, the following hypotheses were set up.

\section{H.III: Employee's Conscientiousness attitude more closely and will have a positive impact on creativity.}

Neuroticism of the five personality types in the propensity to experience the daily life, anxiety, fear, depression, negative emotions, such as self-reproach level and therefore represent an adaptive pattern. If too high, unsafe sex and emotional wellbeing not cope with the stress of the situation is not weakness. Kim \& Yu(1997) study of neurosis in the orientation and job commitment to the organization, behavior, mood inspires action, information sharing and action on the proposed claims were shown the correlation of wealth. In addition, Lee(2004) and other research organizations in the propensity to neurosis communication is to show the correlation of wealth. Based on this previous research the following hypotheses were set up.

\section{H.IV: Neuroticism higher propensity will have a negative impact on creativity.}

Openness to experience, a human of curiosity and out of the world worth pursuing many new ideas and sensitive to their feelings, creative and inquisitive tend to like things. Kim \& $\mathrm{Yu}(1997)$, according to research organization, openness to experience, and dedication to duty behavior, others for help with behavior, mood inspires action, proposed actions and information sharing and (+) shows the correlation was claimed. This leading research based on the following hypothesis was set up.

\section{H. V : Openness to the experience of researchers in higher will have a positive impact on creativity.}

\subsection{Sample and Data Analysis}

Sample of this research consists of 124 employees of 5 firms in Korea. And main sample characteristics are as followings. Age is composed of 20 age period is $48(39 \%), 30$ age period is $40(39.0 \%), 40$ age period is $23(18.7 \%), 50$ age period is $12(3.3 \%)$. Scholarly is high school 59(49.2\%), college $39(32.5 \%)$. Average job tenure is 5.4 year.

Through SPSS 12.0 program, the frequency test about sample characteristics was conducted. And then by the program, confirmatory factor analysis and structural equation model analysis for hypothesis test were carried out.

\section{RESULTS}

\subsection{Measurement Model}

Measurement variables used in the study using the statistical package SPSS factor analysis and reliability analysis was conducted.
Table 2. Result of factor analysis

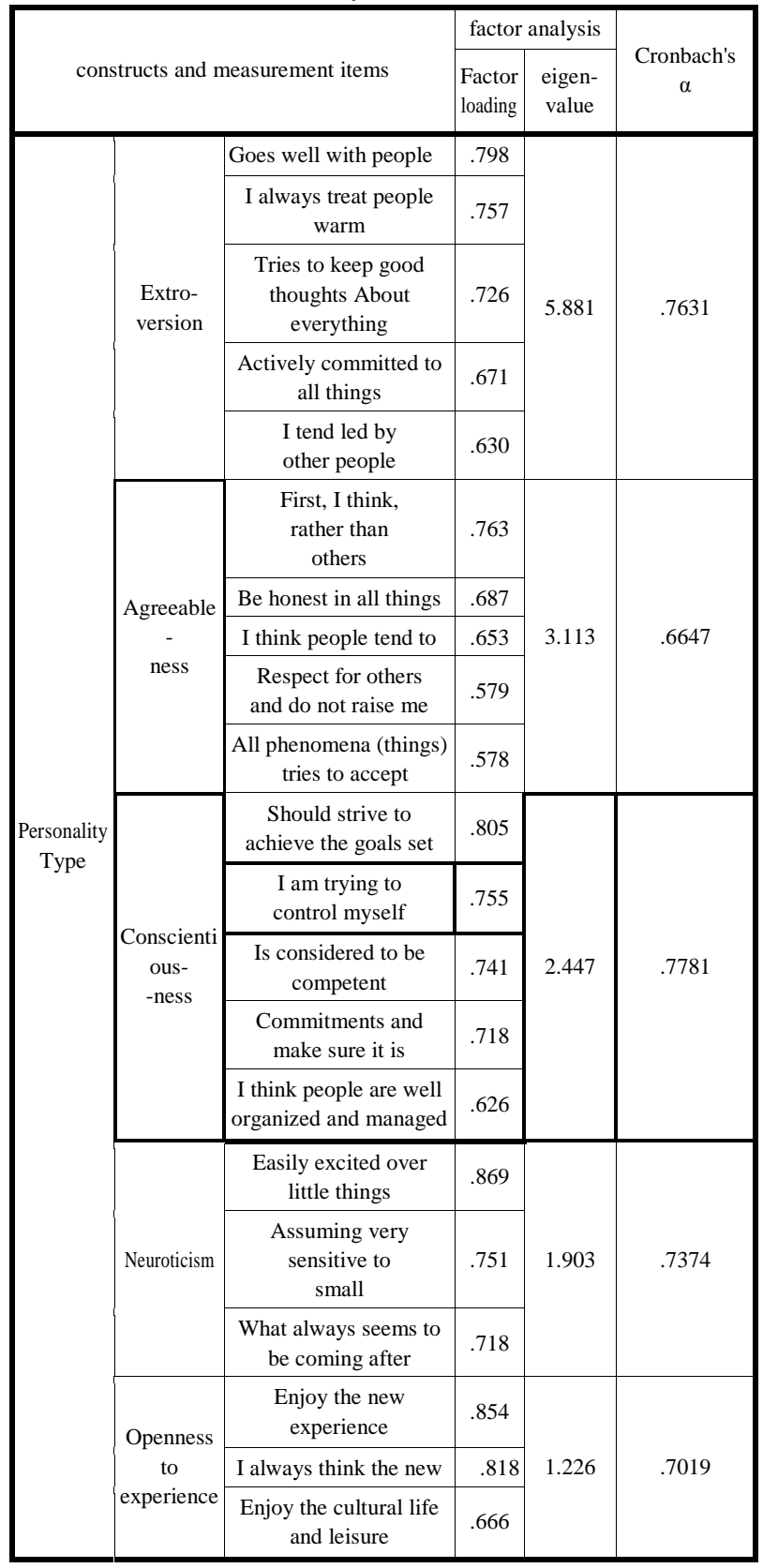

Table 3. Result of factor analysis

\begin{tabular}{|c|c|c|c|c|}
\hline \multirow{2}{*}{\multicolumn{2}{|c|}{$\begin{array}{l}\text { construct concept and } \\
\text { measurement items }\end{array}$}} & \multicolumn{2}{|c|}{$\begin{array}{l}\text { factor analysis } \\
\text { result }\end{array}$} & \multirow{2}{*}{$\begin{array}{c}\text { Cronbach's } \\
\alpha\end{array}$} \\
\hline & & $\begin{array}{c}\text { factor } \\
\text { loading }\end{array}$ & $\begin{array}{l}\text { eigen- } \\
\text { value }\end{array}$ & \\
\hline \multirow{4}{*}{ creativity } & $\begin{array}{l}\text { I rely on the tasks of } \\
\text { completing a high }\end{array}$ & .822 & \multirow{4}{*}{4.041} & \multirow{4}{*}{.8496} \\
\hline & $\begin{array}{l}\text { I am a new area of the } \\
\text { existing methods or tools } \\
\text { are applied to }\end{array}$ & .781 & & \\
\hline & $\begin{array}{l}\text { I have knowledge and } \\
\text { experience in this field are } \\
\text { related }\end{array}$ & .735 & & \\
\hline & $\begin{array}{l}\text { I like companies that are } \\
\text { outside experts in the field }\end{array}$ & .682 & & \\
\hline
\end{tabular}




\begin{tabular}{|c|c|c|c|c|}
\hline & and share opinions & \multirow{2}{*}{} & \\
\cline { 2 - 3 } & $\begin{array}{c}\text { I am a creative new } \\
\text { perspective on all issues } \\
\text { overlook }\end{array}$ & .674 & \multirow{2}{*}{} & \\
\cline { 1 - 3 } $\begin{array}{c}\text { I often say at a meeting of } \\
\text { creative comments }\end{array}$ & .621 & & \\
\hline
\end{tabular}

Factor analysis and reliability analysis of the configuration of the concept aims to verify the validity and reliability, and Varimax rotation factor analysis of the Eigen-value of 1 or more criteria were used to extract factors, the reliability of measurement variables for the analysis of the internal consistency of variables Alpha coefficient representing the Cronbach's $\alpha$ was obtain. Cronbach's $\alpha$ to measure the same concept used for a number of items that hinder the reliable measurement tool for finding items to exclude from the measurement tools to improve the reliability of Cronbach's $\alpha$ values in Nunnally(1967) suggested that the reliability of 0.6 or higher was based on the analysis.

\subsection{Hypothesis Testing}

Hypothesis testing for each of the extracted factors against the independent variables affect the dependent variable to verify that a single regression analysis was conducted, in addition, a single regression analysis, statistical regression expressions were appropriate.

\section{H.1}

Regression analysis for hypotheses 1 and look at the results, the regression model fit the R2 value of 0.380 for validation looked at the population level represents. In addition, the revised model, R2 was the best fit to the population to be modified for the R2, the F-value can be determined. F-value of 19.602 with $\mathrm{P}<.001$ level of statistical significance in the regression expression, because it says you can see established a linear regression expression. In addition, the influence of independent variables on the dependent variable against the average of the input data $=0$, standard deviation $=1$, whether the significance of standardized regression coefficients by the standard regression. Total professor Beta t-value for value, look at the extrovert Beta value is 0.372 , $t$-value of 4.427 to $\mathrm{P}<.001$ significantly at the level of creativity shown to affect the outgoing castle can be seen. Therefore, Hypothesis 1 is adopted.

Table 4. Extroversion of its impact on Creativity, A single regression analysis

\begin{tabular}{|c|c|c|c|c|c|}
\hline \multicolumn{2}{|c|}{ category } & \multicolumn{2}{|c|}{$\begin{array}{c}\text { nonstandardized } \\
\text { coefficients }\end{array}$} & $\begin{array}{l}\text { St a nd ardized } \\
\text { coefficients }\end{array}$ & \multirow{2}{*}{$\mathrm{t}$} \\
\hline $\begin{array}{c}\text { dependent } \\
\text { variable }\end{array}$ & $\begin{array}{l}\text { independent } \\
\text { variable }\end{array}$ & B & $\begin{array}{l}\text { Standard } \\
\text { error }\end{array}$ & $\beta$ & \\
\hline \multicolumn{2}{|c|}{ (constant) } & 1.957 & .334 & & 5.854 \\
\hline creativity & extroversion & .399 & .090 & .372 & $4.427 * * *$ \\
\hline \multicolumn{6}{|c|}{$\mathrm{R}^{2}=.138, \operatorname{Adj} \mathrm{R}^{2}=.131, \mathrm{~F}=19.602 * * *$} \\
\hline
\end{tabular}

\section{H.2}

Regression analysis results for the two hypotheses look, R2 value of 0.061 in the population represents about. In addition, the revised model, R2 was the best fit to the population to modify the score for the R2's. The F-value of 7.961 to determine the results have appeared, $\mathrm{P}<.001$ level of statistical significance in the regression expression, because it says you can see established a linear regression expression. In addition, the influence of independent variables on the dependent variable, looking for, friendly, Castle Beta value is 0.248 , $t$ value of 2.823 to $\mathrm{P}<.01$ significantly at the level of creativity shown to affect sex-friendly can be seen. Therefore, hypothesis 2 is adopted.

Table 5. Agreeableness of its impact on creativity, A single regression analysis

\begin{tabular}{|c|c|c|c|c|c|}
\hline \multicolumn{2}{|c|}{ category } & \multicolumn{2}{|c|}{$\begin{array}{c}\text { nonstandardized } \\
\text { coefficients }\end{array}$} & $\begin{array}{l}\text { Standardized } \\
\text { coefficients }\end{array}$ & \multirow{2}{*}{$\mathrm{t}$} \\
\hline $\begin{array}{c}\text { dependent } \\
\text { variable }\end{array}$ & $\begin{array}{c}\text { Indepen-dent } \\
\text { variable }\end{array}$ & B & $\begin{array}{c}\text { standard } \\
\text { error }\end{array}$ & $\beta$ & \\
\hline \multicolumn{2}{|c|}{ (constant) } & 2.440 & .351 & & 6.950 \\
\hline creativity & Agreeableness & .275 & .097 & .248 & $\begin{array}{r}2.823 \\
* *\end{array}$ \\
\hline \multicolumn{6}{|c|}{$\mathrm{R} 2=.061$, Adj $\mathrm{R} 2=.054, \mathrm{~F}=7.961 * * *$} \\
\hline
\end{tabular}

$*=\mathrm{P}<.05, * *=\mathrm{P}<.01, * * *=\mathrm{P}<.001$

\section{H.3}

Regression analysis results for the three hypotheses examine, $\mathrm{R} 2$ value of 0.394 in the population represents about, revised, and R2 is $0.389, \mathrm{~F}$ value of 79.232 is appearing in this expression is a linear regression $\mathrm{P}<.001$ level indicate a statistically significant can be established. In addition, the influence of independent variables on the dependent variable, looking for, sincerity Beta value is $0.627, \mathrm{t}$-value of 8.901 to $\mathrm{P}<.001$ level of integrity in the castle appears very significantly to affect the creativity can be seen. Therefore, Hypothesis 3 is adopted.

Table 6. Conscientiousness of its impact on creativity, A single regression analysis

\begin{tabular}{|c|c|c|c|c|c|}
\hline \multicolumn{2}{|c|}{ category } & \multicolumn{2}{|c|}{$\begin{array}{l}\text { nonstandardized } \\
\text { coefficients }\end{array}$} & \multirow{2}{*}{$\begin{array}{c}\text { Standardizedcoefficients } \\
\beta\end{array}$} & \multirow[b]{2}{*}{$\mathrm{t}$} \\
\hline $\begin{array}{c}\text { dependent } \\
\text { variable }\end{array}$ & $\begin{array}{c}\text { independent } \\
\text { variable }\end{array}$ & B & $\begin{array}{c}\text { standard } \\
\text { error }\end{array}$ & & \\
\hline \multicolumn{2}{|c|}{ (constant) } & .890 & .287 & & 3.098 \\
\hline creativity & $\begin{array}{l}\text { Conscientio- } \\
\text { usness }\end{array}$ & .692 & .078 & .627 & $8.901 * * *$ \\
\hline \multicolumn{6}{|c|}{$\mathrm{R} 2=.394$, Adj $\mathrm{R} 2=.389, \mathrm{~F}=79.232 * * *$} \\
\hline
\end{tabular}

\section{H.4}

Regression analysis results for hypothesis 4 look, R2 value is .000, -.008 appears as a modified R2 F-value is 0.017 for this appears to have, does not constitute a linear regression expression. In addition, the influence of independent variables on the dependent variable, looking for, neurological Beta value 
of 0.012 only statistically significant results appear to indicate that anxiety is not creativity will not have any effects can be seen. Therefore, hypothesis 4 is rejected.

Table 7. Neuroticism of its impact on creativity, A single regression analysis

\begin{tabular}{|c|c|c|c|c|c|}
\hline \multicolumn{2}{|c|}{ category } & \multicolumn{2}{|c|}{$\begin{array}{l}\text { nonstandardized } \\
\text { coefficients }\end{array}$} & $\begin{array}{c}\text { Standardized } \\
\text { coefficients }\end{array}$ & \multirow{2}{*}{$\mathrm{t}$} \\
\hline $\begin{array}{l}\text { dependent } \\
\text { variable }\end{array}$ & $\begin{array}{l}\text { independent } \\
\text { variable }\end{array}$ & B & $\begin{array}{c}\text { Standard } \\
\text { error }\end{array}$ & $\beta$ & \\
\hline \multicolumn{2}{|c|}{ (constant) } & 3.395 & .198 & & 17.109 \\
\hline creativity & Neuroticism & $\left|\begin{array}{r}8.252 \mathrm{E}- \\
03\end{array}\right|$ & .064 & .012 & .129 \\
\hline \multicolumn{6}{|c|}{$\mathrm{R} 2=.000$, Adj $\mathrm{R} 2=-.008, \mathrm{~F}=.017$} \\
\hline
\end{tabular}

\section{H.5}

Regression analysis for hypotheses 5 and look at the results, $\mathrm{R} 2$ value of 0.167 in the population represents about, revised, and R2 is 0.160 , F-value of 24.387 is appearing in this expression is a linear regression $\mathrm{P}<.001$ level indicate a statistically significant can be established. In addition, the influence of independent variables on the dependent variable, looking for, open the castle and the Beta value of 0.408, t-value of 4.938 to $\mathrm{P}<.001$ level appears very significantly affects openness to creativity can be seen. Therefore, hypothesis 5 is adopted.

Table 8. Openness of its impact on creativity, A single regression analysis

\begin{tabular}{|c|c|c|c|c|c|}
\hline \multicolumn{2}{|c|}{ category } & \multicolumn{2}{|c|}{$\begin{array}{c}\text { nonstandardized } \\
\text { coefficients }\end{array}$} & \multirow{2}{*}{$\begin{array}{c}\begin{array}{c}\text { Standardized } \\
\text { coefficients }\end{array} \\
\beta\end{array}$} & \multirow{2}{*}{$\mathrm{t}$} \\
\hline $\begin{array}{l}\text { dependent } \\
\text { variable }\end{array}$ & $\begin{array}{c}\text { independent } \\
\text { variable }\end{array}$ & B & $\begin{array}{c}\text { standard } \\
\text { error }\end{array}$ & & \\
\hline \multicolumn{2}{|c|}{ (constant) } & 2.090 & .274 & & 7.633 \\
\hline creativity & $\begin{array}{l}\text { Openness to } \\
\text { experience }\end{array}$ & .387 & .078 & .408 & $4.938 * * *$ \\
\hline \multicolumn{6}{|c|}{$\mathrm{R} 2=.167$, Adj $\mathrm{R} 2=.160, \mathrm{~F}=24.387 * * *$} \\
\hline
\end{tabular}

\section{CONCLUSION}

\subsection{Summery and Implication}

In this study, big five personality types of employees have any impact on their creativity, not a big five for a systematic and comprehensive study of literary research and demonstration studies were parallel. Research model that affect the creativity of the employees in the preceding five variables include personality types were selected. The dependent variable in this study as the creativity of researchers and practitioners accept this study was to set up. Hypothesis 1 for the simple regression analysis conducted to validate the results of the employees in the extroversion of their creativity, showed no significant impact. To verify the hypothesis 2 for the regression analysis of employees of the agreeableness of their creativity
(+) showed the impact. Hypothesis 3, regression analysis conducted to validate the results of their creativity of the employees in good faith (+) appeared to affect. Hypothesis 4 results regression analysis for verifying the employee's propensity to neurosis does not have any effects on the creativity found. To verify the hypothesis 5 for the regression analysis results of five employees for their experience, creativity, openness to researchers tablets $(+)$ showed the impact. The personal nature of his work or choose to adapt the job to affect the organization as well as the fact that work life and personal attributes or job, depending on the pattern of mutual adaptation of the organization affect the performance or personal satisfaction is. Psychologists, despite several negative findings, personality characteristics to perform their jobs believed to have been directly affected. Earnest in the 1960s, after the five characteristics of the proposed model is the nature of individual personality characteristics from a psychologist to explain the individual differences that have been recognized as a comprehensive, stable structure, which in turn is associated with a variety of companies and research has led. Characteristics of the five factor model of personality structure, on a proper debate about the validity implies that one of the most popular models so as to influence the status and recognition rather to the full studies now being utilized. Based on this research topic and the research model was set up as a hypothetical set of hypotheses and verified the results obtained the following conclusions could pay. Results of the research staff of the extroversion, agreeableness of their creativity $(+)$ showed the impact. In addition, sincerity, openness to experience, personality and creativity of employee tablets $(+)$ for influencing said. Neurosis to creativity, but nature does not affect any found. Given the results of these studies require creativity, such as a laboratory to test the nature of the employees throughout the organization outgoing and agreeableness and honesty of the owner, including tips on starting an effort to streamline the organization's basic purpose of trying to achieve will be required. This study, five personality types that affect employee creativity of individuals by examining the relationship between personality type and creativity by presenting a model for the study, employees' personality types can have on creativity and offers a realistic alternative to the theory presented you can find the meaning in that. These theoretical and empirical validation of the results of employee productivity oriented organizations, including human resource management in a systematic and reasonable for the type of personality tests are being conducted on the administrative feasibility is expected to be able to provide.

\subsection{Suggestions}

Limitations in this study and future research directions of research are as follows. First, this study surveys the research methods used by the way, because his written entirely subjective (self-reporting) by the survey data as a subjective assessment of the practical value that the respondents accurately reflect the level of perception is not guaranteed. In other words, appropriate laboratory studies such as that were unable to control the situation is not. Therefore, previous research dealing turned a number of other situations 
demonstrated by the analysis of variables that have been affected can't be ruled out. Therefore, the combination of qualitative research method is required. Second, the limitations of the sample can be selected. This research studies the practical matters of environmental conditioned aware, the sample is selected on the radio without the use of sampling, convenient for sampling was used. As a result, the industry respondents, gender and distribution have been biased, and because of this, the generalization of research results and possibilities are limited. In particular, only one laboratory workers surveyed by the organization look so common to think there is somewhat insufficient. Third, the measurement tools used in this study was developed from a foreign state because it forms a group for investigating the use of tablets, but between the linguistic measures can't guarantee full equality. Therefore, future research on the five personality type and creativity that reflects the unique aspects of the development of a measure is necessary. Therefore, future research directions to overcome these limits access to hope.

\section{REFERENCE}

[1] D.W.Fiske, "Consistency of the factorial Structures of Personality Ratings from different Sources.: Journal of Abnormal And Social Psychology, vol.44, 1949. pp.329-344.

[2] D.Y.Kim and T.Y.Yu,"a variety of direct military in nature, the 5 factors andduties", the relationship between corporatemanagement research. 1997. The 5th Kwangwoon University Corporate Management Institute: 69-94 in quotes (Mount, M. K., \& Barrick, M. R. 1995.

[3] E.C. Tupes and R.E. Christal, Recurrent Personality Factors Based on Trait Ratings. USAF ASD Technical Report, 1961. pp.61-97.

[4] F. Barron and D.M.Harrington, "Creativity, Intelligence and Personality", Annual Review of Psychology. vol.32, 1981. pp. 439-476.

[5] G .B.Baek, "Organizational Behavior Research", Changminsa. 2002.

[6] H. Gardner, "Creating Minds". New York: Basic Books. 1993.

[7] I.S.Choe, "creativity for understanding," the six questions. Korea Psychology : General, vol.17. no.1, 1998. pp.25-27.

[8] J.C. Nunnally, Psychometric Theory, New York, NY: McGraw-Hill. 1978.

[9] J.H.Park, "comparative culture in psychology approach study on globalization". Yeungnam University Humanities Research, vol.27, 2001. pp.33-49.

[10] J.I.Choe, "the collective creativity of the determining factor in the study" in quotes (Parnes, S. J. 1977. "GPSI : The general System. 1995.

[11] J.K.Kim, "the personal characteristics and organization of the members of the creative act situation impact study", Seoul National University graduate, masters degree thesis. 1997.
[12] J.P.Guildford and W.S.Zimmerman, "The GuilfordZimmerman Temperament Survey." Beverly Hills, CA: Sheridan Supply. 1949.

[13] M. Csikszentmihalyi, " Creativity : Floe and and Psychology of Discovery and Invention", New York. Harper Collins. 1996.

[14] P. Suvagondh, Relationships among creative Style Preference, Job Satisfaction, and Work Environment. Alliant International U, San Diego, US. 2003.

[15] R.J.Sternberg and L. A. O'hara, "Creativity and Intelligence" in Sternberg: 1999. pp.251-272.

[16] R.M. Kanter, The Change master. New York:Simon \& Schuster. 1983.

[17] R.R.McCrae and P.T. Costa, "Validation of the fiveFactor Model of Personality across Instruments and Observers. " Journal of Personality and Social Psychology. vol. 52, 1987. pp. 81-90.

[18] S.H.Lee and S.G.Kim \& J.N.Choi, "Organization and personal nature of the Organization and its impact on the immersed", Korea administration a thesis vol.16. no. 4, 2004. pp.735-757.

[19] T.M.Amabile, "A Model of Cerativity and Innovation in Organization". In B. M Staw \& L. L. Cummings(Eds), Research in Organizational Behavior, vol. 10, 1998. pp.123-167.

[20] U.K.Lee, "domestic science and technology workforce creative research empowerment measures" . 2003.

[21] U.S.Song and J.H.Kim, "the personal character of the intermediate-petty official and organization citizen behaviour of relationship : job autonomy of adjustment effects, mainly", Journal of political science, and vol.36. no. 1, 2002, pp.117-137.

[22] W.C.Borman and S.J.Motowidlo, "Expending the Criterion Domain to include elements of contextualPerformance." InN. Schmit \& W.C. Borman(Eds), Personnel Selection in Organizations(pp.71-98). San Francisco: Jossey-Bass. 1993.

[23] W.T.Norman. "Toward an adequate Taxonomy of Personality Attribute: Replicated Factor Structure in Peer Nomination Ratings." Journal of Abnormal and Social Psychology. vol.66, 1963. pp.574-583. 


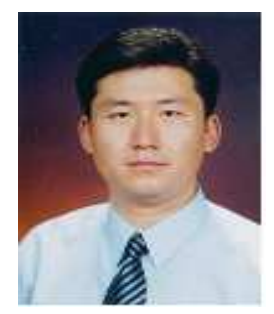

Kil-Whoan Lee

$\mathrm{He}$ received the $\mathrm{Ph}$. D. from Chungbuk National University, Korea. $\mathrm{He}$ is currently a HRM part time lecturer of Chungbuk University. His main interests include HRM, Industrial Relations and Business Ethics.

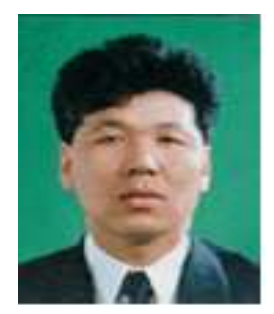

\section{Jin-Hee Park}

$\mathrm{He}$ received the MBA from Korea University of Technology and Education. His main interests include HRM, Industrial Relations and Technology

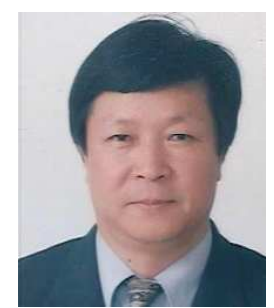

\section{Ha-Sik Song}

He received the $\mathrm{Ph}$. D. from Chungbuk National University, Korea. $\mathrm{He}$ is currently a HRM part time professor of Chungbuk University. His main interests include HRM, Industrial Relations and Business Ethics. 